\title{
ELECTROLYTE CONTENT OF EXTRACELLULAR FLUID IN HEALTH AND IN CONGESTIVE HEART FAILURE
}

\author{
BY \\ C. T. G. FLEAR* AND PAT HUGHES $\dagger$ \\ From the Queen Elizabeth Hospital, Birmingham, and the Department of Experimental Medicine, Cambridge \\ Received May 6, 1962
}

In the course of routine management of patients in congestive heart failure in whom frequent analyses of serum were made, it became apparent that levels of electrolytes were commonly abnormal judged by published normal values (Wootton, King, and Smith, 1951; Wootton and King, 1953) even in patients responding well to treatment. Moreover the levels often varied quite considerably over a period of days or weeks. Wootton and King (1953) have, however, drawn attention to the wide differences that may obtain between estimations in different routine laboratories and it therefore seemed worth while analysing serum from healthy subjects to see if we were justified in using the published normal values as standards for comparison, and to obtain an estimate of the variability in serum levels found in healthy subjects over a period of several days. At the same time the variability of serum levels of electrolytes was studied in 73 patients throughout the period of their admission to hospital in congestive heart failure. Our findings are presented in this paper.

\section{SubJeCTS AND METHODS}

Normal Subjects. In order to find the distribution of serum levels in health, one sample of blood was taken from each of 157 healthy doctors, nurses, students, technicians, and various non-resident hospital employees. The group contained 85 men and 72 women, and their ages ranged from 16-55 years.

In order to determine the variability of serum levels in the same person, serum from two healthy men and one healthy woman was analysed on each of 11 days over a period of two weeks. Nine samples of serum were also taken over 11 days in a second healthy woman.

Patients in Congestive Heart Failure. The patients studied were 36 men and 37 women in congestive heart failure who were consecutive admissions to one hospital ward. No other criteria were involved in their selection, and cases are included of varying ætiology, rheumatic, hypertensive, cor-pulmonale, etc. All patients were under the care of the same physician (Dr. O. Brenner). During the period of study, all patients were at rest in bed, all were taking dig. folia, and all were receiving regular intramuscular injections (two to three per week) of a mercurial diuretic thiomerin (mercaptomerin) unless their blood urea rose above $70 \mathrm{mg} . / 100 \mathrm{ml}$. (Brenner, 1960). The patients were encouraged to drink freely, and fluid intake was self selected. All patients were receiving anticoagulants. In other respects treatment was determined by individual circumstances (Brenner, 1960). The patients were classified in retrospect according to clinically assessed outcome, as follows.

1 Quick response: improvement beginning as soon as patient put to bed in hospital; free from objective signs of heart failure within three weeks.

2. Moderate response: no improvement for fortnight; all objective signs of heart failure disappearing after a further few weeks.

3. Slow to no response: no more than gradual improvement and no complete resolution of all signs of

* Beit Memorial Research Fellow. Present address: Queen Elizabeth Hospital, Birmingham.

$\dagger$ Present address: Department of Biochemistry, The Children's Hospital, Birmingham. 
heart failure; loss of odema (reflected in increased urine output and loss of weight) did not begin for at least three weeks after admission to hospital.

4. Died in hospital.

For convenience the terms mild, moderate, and severe non-fatal or fatal are applied to these four categories.

Blood was taken on admission and thereafter on three days in each week throughout stay in hospital. A minimum of six sera were analysed from each patient, usually more.

Technical Details. All blood samples were taken in the mornings, two to three hours after breakfast, using dry all-glass syringes and with minimal venous stasis. Serum was separated within one hour of taking the blood and was analysed for sodium and potassium using an E.E.L. flame photometer, and for chloride using the Volhard titrimetric method. All sera were estimated along with other routine estimations. Coefficients of variation (standard deviation of values, expressed as a percentage of the mean of the observed values) are used as summarizing indices of variability in the patients and normal subjects. The distribution of data from the 157 healthy subjects was examined for skewness and excess according to methods described by Lindeberg (1924).

Variability that may arise from the routine estimation of sera on different days also has been assessed. On three occasions, at widely separated periods over two years, a fairly large volume of pooled serum was obtained. The serum was not specially labelled and on several successive days $(13,25$, and 16$)$ was analysed for sodium, potassium, and chloride, during the course of other routine examinations of sera from wards in the hospital. The coefficients of variation ranged from 0.62 to 1.56 per cent for sodium (mean $1.20 \%$ ), and from 1.52 to 2.37 per cent for potassium (mean $2.08 \%$ ), and from 0.37 to 1.43 per cent for chloride (mean $0.93 \%$ ). Also for comparison seven samples of serum from bottled blood from a hypertensive subject were analysed during the course of routine estimations on one day. The coefficients of variation were 0.40 per cent for sodium, 0.47 per cent for potassium, and 0.45 per cent for chloride.

\section{RESULTS}

Normal Subjects. The distribution of serum levels in health are presented in Table I. Much the same values were found for serum electrolytes as those reported by Wootton and King (1953). In our series, however, the distribution of values for sodium and chloride showed a significant degree of skewness while values for serum potassium did not show any skew. There was no obvious correlation between age or sex and serum levels. Josephson and Dahlberg (1952) reported a correlation between age and serum sodium, the sodium level falling with old age. This may have been due to their values at the upper age range, deriving from hospital controls and residents from an old folk's home.

TABLE I

Values for Serum Levels found in Healthy Subjects of both Sexes, aged 16-55 Years

\begin{tabular}{|c|c|c|c|c|}
\hline Substance & $\begin{array}{l}\text { Number of } \\
\text { observations }\end{array}$ & Mean & $\begin{array}{l}95 \% \text { confidence } \\
\text { limits }+\end{array}$ & Comments \\
\hline Sodium $(\mathrm{mEq} / \mathrm{l}.) \quad \ldots$ & 157 & 138 & $132-144$ & Skew distribution with more observa- \\
\hline $\begin{array}{l}\text { Potassium (mEq/1.) } \\
\text { Chloride (mEq/l.) .. }\end{array}$ & $\begin{array}{l}157 \\
151\end{array}$ & $\begin{array}{l}4 \cdot 3 \\
106\end{array}$ & $\begin{array}{r}3 \cdot 4-5 \cdot 2^{*} \\
101-111 \dagger\end{array}$ & Skew distribution with more observa- \\
\hline $\mathrm{Na} / \mathrm{Cl}$ ratio . . & 151 & $1 \cdot 292$ & $1 \cdot 196-1 \cdot 388 \dagger$ & $\begin{array}{l}\text { Skew distribution with more observa- } \\
\text { tions falling above mean than below }\end{array}$ \\
\hline
\end{tabular}

*Significant negative excess. + Significant positive excess. + (mean $-2 \mathrm{SD})-($ mean $+2 \mathrm{SD})$.

Where there is negative excess the limits so calculated will enclose more than $95 \%$ of the observations; and where positive they will enclose less than $95 \%$.

The variability of serum levels in the four healthy subjects agreed well with that reported by Fawcett and Wynn (1956) in healthy subjects observed for a longer period of two to six months. The coefficients of variation that we observed in healthy male subjects were 1.0 and 1.4 per cent for 
sodium, 6.9 and 8.0 per cent for potassium, and 1.7 and 1.4 per cent for chloride. In the women the values were 0.5 and 0.6 per cent for sodium, 6.2 and 5.2 per cent for potassium, and 1.9 and 1.8 per cent for chloride. The average coefficients of variation were 0.95 per cent for sodium, 6.8 per cent for potassium, and 1.7 per cent for chloride.

Patients in Congestive Heart Failure. Levels of sodium on admission averaged 133, 132, 130, and $128 \mathrm{mEq} / \mathrm{l}$. in the four groups of patient, mild, moderate, severe non-fatal, and severe fatal respectively. The lowest levels attained during the stay in hospital in these same groups averaged $128,126,125$, and $121 \mathrm{mEq} / 1$. respectively. On admission the similar levels of chloride were 102 , 101,102 , and $98 \mathrm{mEq} / 1$.: lowest levels were $97,95,95$, and $88 \mathrm{mEq} / 1$. respectively for the groups in the same order as listed for sodium. Potassium levels on admission averaged $4 \cdot 3,4 \cdot 7,4 \cdot 8$, and $5.0 \mathrm{mEq} / 1$. respectively. Again in the same order, the highest levels of potassium attained during the admissions averaged $4 \cdot 8,5 \cdot 2,5 \cdot 7$ and $6.3 \mathrm{mEq} / 1$. Table II summarizes the incidence of abnormal serum levels in these patients.

Variability of sodium and potassium in patients in congestive heart failure is presented in Tables III and IV and Fig. 1 to 4 . The variability of chloride is not presented since it paralleled that shown by sodium.

TABLE II

Incidence of Abnormal Levels on Admission and Subsequently in 73 Patients in Congestive HeART FAILURE

\begin{tabular}{|c|c|c|c|c|c|c|c|}
\hline \multirow{2}{*}{\multicolumn{2}{|c|}{ Group }} & \multicolumn{2}{|c|}{ Low sodium levels } & \multicolumn{2}{|c|}{ Low chloride levels } & \multicolumn{2}{|c|}{ Raised potassium levels } \\
\hline & & admission & subsequently & admission & subsequently & admission & subsequently \\
\hline $\begin{array}{l}\text { Mild .. } \\
\text { Moderate .. } \\
\text { Severe, non-fatal } \\
\text { Severe, fatal .. }\end{array}$ & $\begin{array}{l}\ldots \\
\ldots\end{array}$ & $\begin{array}{r}4 / 8(50 \%) \\
7 / 14(50 \%) \\
11 / 18(61 \%) \\
25 / 33(76 \%)\end{array}$ & $\begin{array}{r}8 / 8(100 \%) \\
12 / 14(86 \%) \\
18 / 18(100 \%) \\
33 / 33(100 \%)\end{array}$ & \begin{tabular}{|}
$2 / 8(25 \%)$ \\
$7 / 14(50 \%)$ \\
$8 / 18(44 \%)$ \\
$20 / 33(60 \%)$
\end{tabular} & $\begin{array}{r}7 / 8(88 \%) \\
13 / 14(93 \%) \\
16 / 18(88 \%) \\
32 / 33(97 \%)\end{array}$ & $\begin{array}{|rr|}0 / 8 & (0 \%) \\
1 / 14 & (7 \%) \\
4 / 18 & (22 \%) \\
10 / 33 & (30 \%)\end{array}$ & $\begin{array}{r}2 / 8(25 \%) \\
6 / 14(43 \%) \\
9 / 18(50 \%) \\
28 / 33(85 \%)\end{array}$ \\
\hline
\end{tabular}

TABLE III

Variability in Serum Sodium Levels (Coefficients of Variation Per cent) in Patients in Congestive Heart Failure

\begin{tabular}{c|c|c|c}
\hline $\begin{array}{c}\text { Coefficient } \\
\text { of variation }\end{array}$ & Mild, moderate & Severe, non-fatal & Severe, fatal \\
\hline \begin{tabular}{l|l}
$52 \cdot 7$ \\
$>2 \cdot 7-4.0$
\end{tabular} & $12(55 \%)$ & $7(39 \%)$ & $5(15 \%)$ \\
$>4 \cdot 0$ & $2(36 \%)$ & $7(39 \%)$ & $15(45 \%)$ \\
\hline Total (73) & 22 & $4(22 \%)$ & $13(39 \%)$ \\
\hline
\end{tabular}

Data from 73 patients grouped according to their response to treatment (see text).

TABLE IV

Variability in Serum Potassium LeVels (Coefficients of Variation Per CENT) In Patients in Congestive Heart Failure

\begin{tabular}{|c|c|c|c|}
\hline $\begin{array}{l}\text { Coefficient } \\
\text { of variation }\end{array}$ & Mild, moderate & Severe, non-fatal & Severe, fatal \\
\hline $\begin{array}{l}\leqslant 9 \cdot 5 \\
>9 \cdot 5-15.0 \\
>15.0\end{array}$ & $\begin{array}{r}12(55 \%) \\
7(32 \%) \\
3(14 \%)\end{array}$ & $\begin{array}{l}6(33 \%) \\
8(44 \%) \\
4(22 \%)\end{array}$ & $\begin{array}{r}5(15 \%) \\
12(37 \%) \\
16(49 \%)\end{array}$ \\
\hline Total (73) & 22 & 18 & 33 \\
\hline
\end{tabular}

Data from 73 patients grouped according to their response to treatment (see text). 


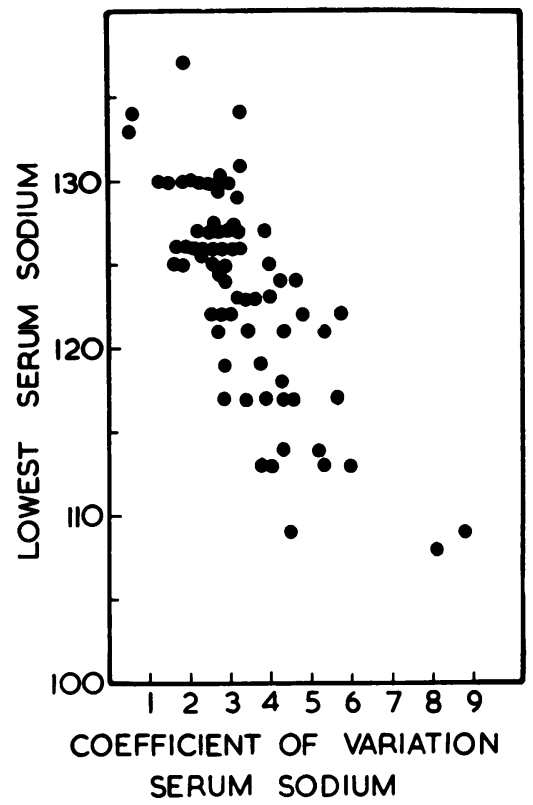

Fig. 1.-Lowest serum levels of sodium during admission, and the variability in serum levels of sodium in 73 patients in congestive heart failure.

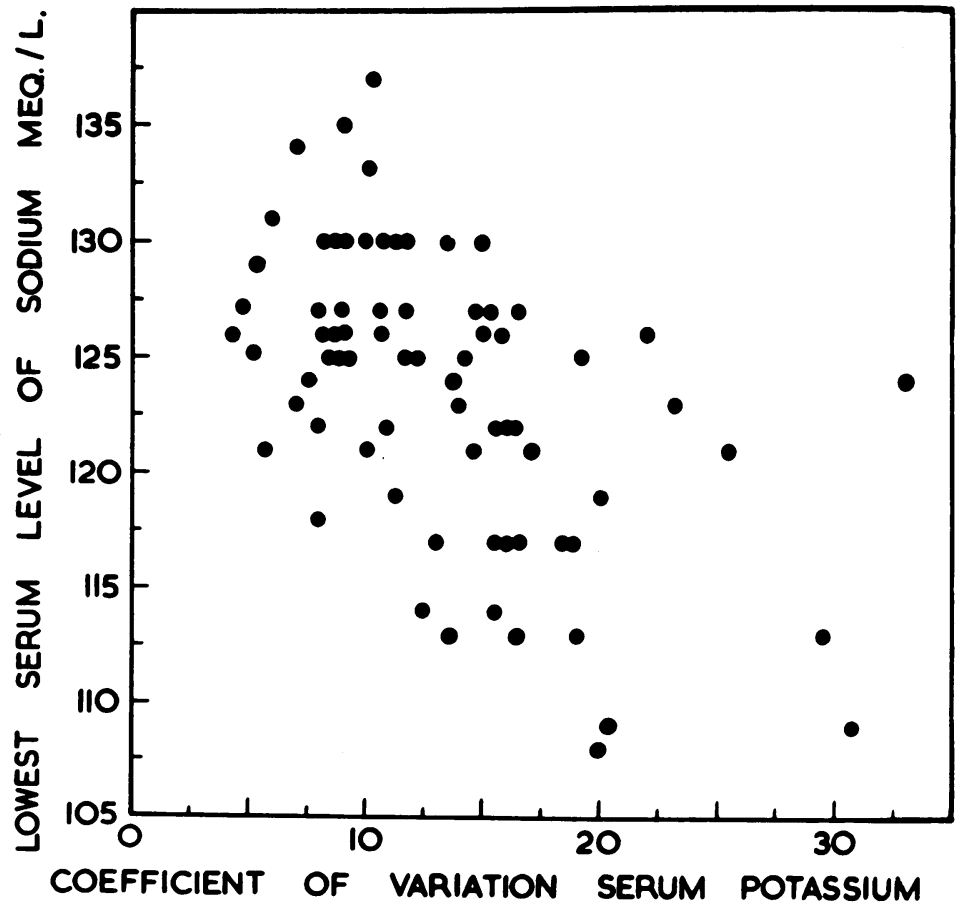

FIG. 2.-Lowest serum levels of sodium during admission, and the variability in serum levels of potassium in 73 patients in congestive heart failure. 
The average values for the group of healthy subjects are close to those reported by Fawcett and Wynn (1956), but our standard deviations are larger. This is probably because our values were obtained in a manner simulating, as closely as possible, the circumstances under which routine requests are handled by the laboratory. The values and standard deviations are in good agreement with those reported by Wootton et al. (1951) and by Wootton and King (1953).

Patients in congestive heart failure in this study commonly had abnormally low levels of sodium and chloride on admission. Potassium levels were sometimes raised. The incidence of these abnormalities increased during and after admission (Table II). This is the common finding in 

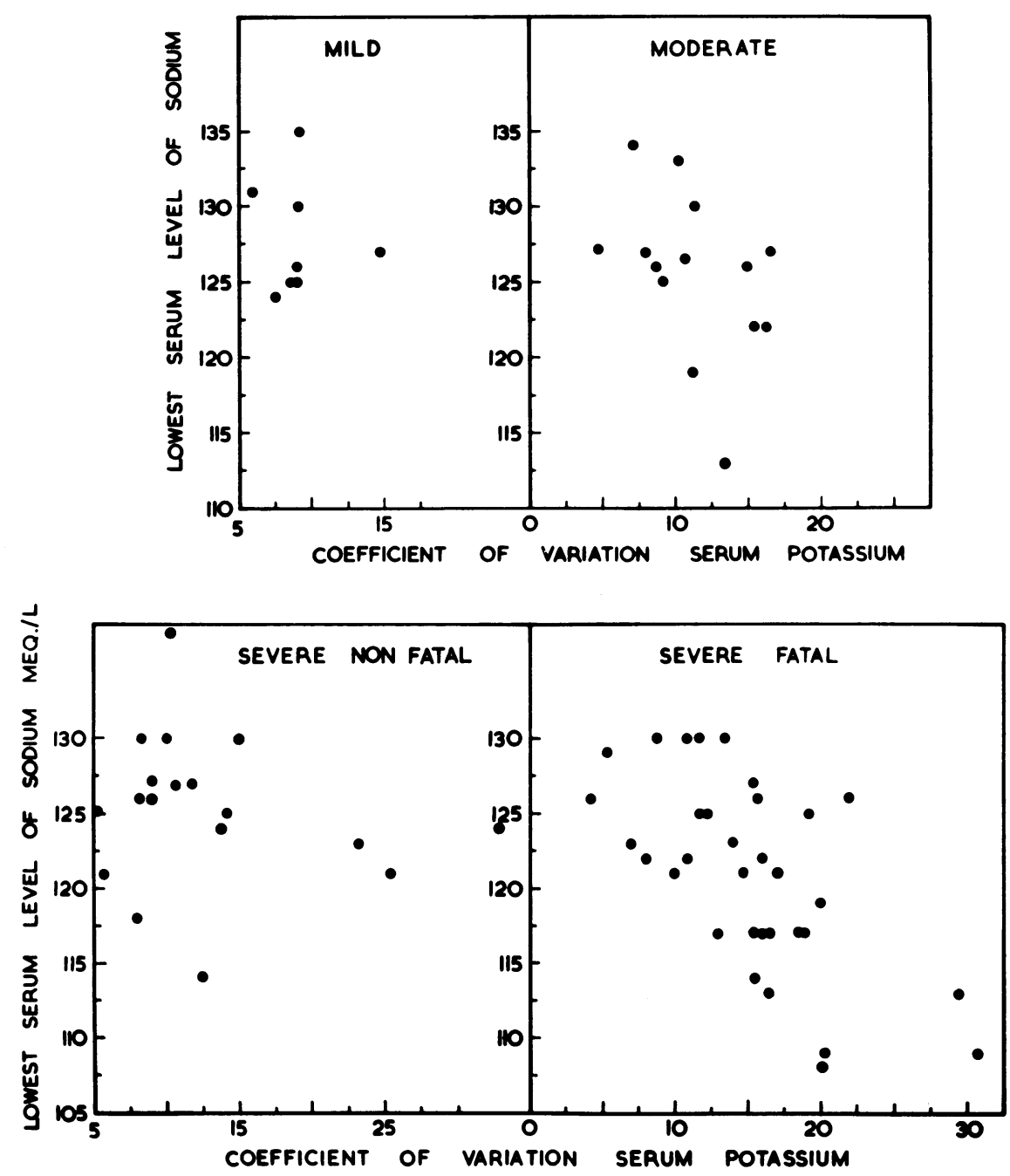

FIG. 4.-Lowest serum levels of sodium during admission and the variability in serum levels of potassium in 73 patients in congestive heart failure. The patients have been placed into four categories according to their response to treatment (see text).

congestive heart failure, however treated (Flear, 1960a and b). Serum levels in these patients were also more variable than in health, indicating that regulation of the milieu interne is often less precise in congestive heart failure than in health. The contribution made by treatment to this is not defined by this study, but it is significant that the extent of fluctuation in serum levels correlates well with the classification of patients adopted. Thus the group of patients who died contains a greater proportion showing extensive fluctuations in serum levels than does the group of patients showing quick or moderate response to treatment (Tables III and IV). Conversely the latter groups contain a higher proportion of patients whose serum levels fluctuated only a little more than in health (Tables III and IV). It is significant too, that the variability in serum levels correlates well with the lowest level of sodium obtained during the admission: the lower the level, the less steady the levels of sodium or potassium (Fig. 1 and 2), and also of chloride. For sodium this 
is so in all groups of patients (Fig. 3), but in the case of potassium the correlation is really only striking in the group of patients who died (Fig. 4). It is true that this classification of patients is a purely pragmatic one which must at times conceal differences, since a patient may respond slowly to treatment for instance for many different reasons. Nevertheless our results prompt the suggestion that the more severe or complex the episode of congestive heart failure, the less finely controlled are the levels of sodium, potassium, and chloride in the extracellular fluids.

Falls in serum levels of sodium have been noted to follow most severe complications arising in congestive heart failure (Flear, 1960b; Weston et al., 1958) and it has been suggested that, in some patients, retention of water, prompted by a need to maintain or expand the circulating blood volume or cardiac output, is a factor in their onset. Perhaps, therefore, such a need contributes to the variability in levels of sodium and chloride in extracellular fluid, since correction of a fall in the serum level of sodium would entail an increased excretion of water and an undesirable fall in plasma volume. It is unlikely, however, to contribute to instability in the level of potassium. Perhaps, therefore, cellular factors contribute by making the distribution of ions between cellular and extracellular fluids less steady than in health. Evidence that this distribution of ions may differ from normal in congestive heart failure has been submitted elsewhere (Flear and Crampton, 1960; Flear, Crampton, and Matthews, 1961; Flear, Campana, and Florence, 1961).

\section{SUMMARY}

Serum from 157 healthy subjects of both sexes was analysed for sodium, potassium, and chloride. Much the same values were noted as previously reported for normal subjects by Wootton and King (1953). Average values found were sodium $138 \mathrm{mEq} / 1$, potassium $4.3 \mathrm{mEq} / 1$, , and chloride 106 $\mathrm{mEq} / \mathrm{l}$.

Serum was also analysed in four healthy subjects, two men and two women, at approximately daily intervals for about two weeks. In all four, variability of sodium, potassium, and chloride over this period was less than for the group of 157 healthy subjects. The average coefficients of variation were sodium 0.95 per cent, potassium 6.8 per cent, chloride 1.7 per cent. For the group of 157 healthy subjects the coefficients of variation were $2 \cdot 1,10 \cdot 3$, and $2 \cdot 5$ per cent respectively.

Serum was analysed for sodium, potassium, and chloride on admission in 73 patients in congestive heart failure, and three times each week while in hospital. Levels of all three electrolytes were frequently abnormal, sodium and chloride tending to be low, potassium to be raised. These levels were also found to be less steady in most of the patients in congestive heart failure than in the healthy subjects. Greatest variability was found most often in patients in severe congestive heart failure, least variability in those responding quickly or moderately quickly to treatment. It was noted, also, that the lower the level of sodium attained during an episode of congestive heart failure, the greater was the fluctuation in serum levels.

The material presented in this paper was included in an M.D. thesis presented by one of us (C.T.G.F.) to the University of Birmingham. Our thanks are due to D. O. Brenner for his help and encouragement in this study. We would like to thank Mr. T. Whitehead for comments on the manuscript. Part of the expenses incurred in this study were met by a grant from Pfizer Ltd., Sandwich.

\section{REFERENCES}

Brenner, O. (1960). In Modern Trends in Cardiology, ed. A. Morgan Jones, p. 82. Butterworth, London.

Fawcett, J. K., and Wynn, V. (1956). Brit. med. J., 2, 582.

Flear, C. T. G. (1960a). Postgrad. med. J., 36, 104.

(1960b). Studies in congestive heart failure; therapeutic and theoretical problems. M.D. thesis, University of Birmingham.

- Campana, A. O., and Florence, I. (1961). Proc. Ass. clin. Biochem., 1, 128.

-, and Crampton, R. F. (1960). Clin. Sci., 19, 495.

- - - and Matthews, D. M. (1961). Clin. Sci., 21, 381.

Josephson, B., and Dahlberg, G. (1952). Scand. J. clin. Lab. Invest., 4, 216.

Lindeberg, W. (1924). Skand. Aktuarie tidskr., 8, 106.

Weston, R. E., Grossman, J., Borun, E. R., and Hanenson, I. B. (1958). $\quad$ Amer. J. Med., $25,558$.

Wootton, I. D. P., and King, E. J. (1953). Lancet, 1, 470.

$\longrightarrow,-$, and Smith, J. Maclean (1951). Brit. med. Bull., 7, 307. 